\title{
छs \\ Negotiating energy dynamics through embodied action in a materially structured environment
}

\author{
Rachel E. Scherr, ${ }^{1}$ Hunter G. Close, ${ }^{2}$ Eleanor W. Close, ${ }^{2}$ Virginia J. Flood, ${ }^{3}$ Sarah B. McKagan, ${ }^{1}$ \\ Amy D. Robertson, ${ }^{1}$ Lane Seeley, ${ }^{1}$ Michael C. Wittmann, ${ }^{3,4}$ and Stamatis Vokos ${ }^{1}$ \\ ${ }^{1}$ Department of Physics, Seattle Pacific University, Seattle, Washington 98119, USA \\ ${ }^{2}$ Department of Physics, Texas State University, San Marcos, Texas 78666, USA \\ ${ }^{3}$ Maine Center for Research in STEM Education, Orono, Maine 04469, USA \\ ${ }^{4}$ Department of Physics, University of Maine, Orono, Maine 04469, USA
}

(Received 18 January 2013; published 12 July 2013)

\begin{abstract}
We provide evidence that a learning activity called Energy Theater engages learners with key conceptual issues in the learning of energy, including disambiguating matter flow and energy flow and theorizing mechanisms for energy transformation. A participationist theory of learning, in which learning is indicated by changes in speech and behavior, supports ethnographic analysis of learners' embodied interactions with each other and the material setting. We conduct detailed analysis to build plausible causal links between specific features of Energy Theater and the conceptual engagement that we observe. Disambiguation of matter and energy appears to be promoted especially by the material structure of the Energy Theater environment, in which energy is represented by participants, while objects are represented by areas demarcated by loops of rope. Theorizing mechanisms of energy transformation is promoted especially by Energy Theater's embodied action, which necessitates modeling the time ordering of energy transformations.
\end{abstract}

DOI: 10.1103/PhysRevSTPER.9.020105

PACS numbers: 01.40.Fk, 01.40.Ha, 01.40.J-

\section{INTRODUCTION}

Energy is a crosscutting concept in science and features prominently in national science education documents, including the Next Generation Science Standards. Energy plays multiple roles not only in scientific and engineering work but also in larger sociopolitical and economic contexts. National priorities urge us to prepare learners with a deep understanding of energy ideas.

Deep understanding of energy can be elusive. Energy is an abstract concept in the sense that it cannot be operationally defined independent of its specific forms. Like matter, energy obeys a conservation principle, but energy and matter are distinct from one another. Even more challenging than these conceptual issues are issues of interdisciplinary relevance: All scientific and engineering disciplines claim energy as their own, and all conceptualize energy in different, discipline-specific ways [1,2]. Physicists prioritize well-circumscribed systems (such as heat engines) and study energy inputs and outputs, marginalizing the energy changes in the environment of those systems. Biologists, in contrast, may organize systems according to form or function, and track the flow of energy in open systems (such as food webs). Chemists often find concepts such as enthalpy and free energy more useful to their practice than energy itself. Outside all of these

Published by the American Physical Society under the terms of the Creative Commons Attribution 3.0 License. Further distribution of this work must maintain attribution to the author(s) and the published article's title, journal citation, and DOI. disciplinary practices, sociopolitical discourse has its own priorities and language, in which the energy available to serve human purposes is both created (in power plants) and destroyed (in processes that render it unavailable to us). Learners need instructional approaches that respond to these diverse issues.

The Energy Project is a five-year NSF-funded project whose goal is to promote elementary and secondary teachers' development of formative assessment practices in the context of energy. Our goals for energy learning are specific to our population of learners and include conceptual understanding, sociopolitical relevance, creative flexibility, and representational competence. Our progress toward some of these goals is reported elsewhere [3-10]. This paper focuses on conceptual learning of physics content, which is a primary need of elementary and secondary teachers [11-13]. Our primary conceptual learning goal is for learners to conserve energy as they track the transfers and transformations of energy within, into, or out of the system of interest in complex physical processes.

As part of tracking energy transfers among objects, learners should (i) distinguish energy from matter, including recognizing that energy flow does not uniformly align with the movement of matter, and should (ii) identify specific mechanisms by which energy is transferred among objects, such as mechanical work and thermal conduction. As part of tracking energy transformations within objects, learners should (iii) associate specific forms with specific models and indicators (e.g., kinetic energy with speed and/or coordinated motion of molecules, thermal energy with random molecular motion and/or temperature) and 
(iv) identify specific mechanisms by which energy is converted from one form to another, such as incandescence and metabolism. Finally, we hope for learners to be able to optimize systems to maximize some energy transfers and transformations and minimize others, subject to constraints based in both imputed mechanism (e.g., objects must have motion energy in order for gravitational energy to change) and the second law of thermodynamics (e.g., heating is irreversible). We hypothesize that a subsequent goal of energy learning-innovating to meet socially relevant needs-depends crucially on the extent to which these goals have been met.

In order to better illustrate the high aspiration that these goals represent, we offer an analogy from economics [14]. What would it mean for someone to be able to track the transfers and transformations of assets within, into, or out of systems of interest in the American economy? What would one need to know in order to optimize the effect of the Federal Reserve's quantitative easing on unemployment, bond prices, or interest rates? Aphorisms such as "a rising tide lifts all boats" or "energy is conserved" are not sufficient to enable rigorous analysis. Learners need the tools to hypothesize through what means, in what temporal order, and with what observable evidence energy flows dynamically in a specific real-world situation.

We describe a learning activity called Energy Theater that is designed to promote conceptual understanding of energy. Our research addresses the following questions:

- With what specific key conceptual issues of energy do learners engage while doing Energy Theater?

- By what processes does Energy Theater cause learners to engage with those specific conceptual issues?

We provide evidence that Energy Theater supports disambiguating energy and matter [goal (i) above] and theorizing mechanisms for energy transformation [goal (iv) above]. [We expect to address (ii) and (iii) in future work $[8,15,16]$. $]$ We conduct detailed analysis to build plausible causal links between specific features of Energy Theater and the conceptual engagement that we observe, in which learners collaboratively negotiate meaning in a materially structured environment.

\section{ENERGY THEATER}

We structure our energy instruction around a substance metaphor for energy, which supports a model of energy as conserved, localized, transferring among objects, and transforming among forms $[3,4]$. These features constitute a powerful conceptual model of energy that may be used to explain and predict energy phenomena [17-22]. Though this metaphor has limitations [18,23], its benefits for our specific instructional goals outweigh its possible disadvantages [3].

Energy Theater is a learning activity that is based on a substance metaphor for energy [4]. In Energy Theater, each participant identifies as a unit of energy that has one and only one form at any given time. Groups of learners work together to represent the energy transfers and transformations in a specific physical scenario-for example, a refrigerator cooling food, or a light bulb burning steadily. Participants choose which forms of energy and which objects in the scenario will be represented. Objects in the scenario correspond to regions on the floor. As energy moves and changes form in the scenario, participants move to different locations on the floor and change their represented form. The rules of Energy Theater are as follows:

- Each person is a unit of energy in the scenario.

- Regions on the floor correspond to objects in the scenario.

- Each person has one form of energy at a time.

- Each person indicates their form of energy in some way, often with a hand sign.

- People move from one region to another as energy is transferred, and change hand sign as energy changes form.

- The number of people in a region or making a particular hand sign corresponds to the quantity of energy in a certain object or of a particular form, respectively.

Energy Theater represents energy as being conserved, emplaced, and changing form; it explicitly shows energy as being located in objects [24], flowing among objects, and accumulating in objects; and it is a dynamic representation, able to show processes as they unfold as well as "snapshots" of energy at specific instants. These are the features of an energy model that promote detailed tracking of energy transfers and transformations in complex realworld processes $[3,4]$. Learners work together to negotiate this representation of the energy dynamics in a particular scenario with an end goal of enacting the representation in a final performance for their peers.

This paper presents a specific enactment of Energy Theater in which a particular group of learners models energy transfers and transformations for a specific physical scenario: an incandescent light bulb burning steadily. Roughly speaking, electrical energy flows from the base of the light bulb into the filament, where some transforms into thermal energy via the dissipative process of Joule heating. Some of the thermal energy in the filament transforms to light energy that travels outward to the surroundings (incandescence). Thus, while the electric current flows in a closed loop around the circuit, some of the energy flows out into the environment.

An Energy Theater analysis prompts learners to make decisions such as whether to subdivide the relevant objects (e.g., into what part of the bulb does energy flow? Where exactly is the electrical energy transformed into thermal energy?) and how to accurately represent the time order of energy transfers and transformations (e.g., are thermal energy and light energy generated simultaneously or is one generated first?). Comparable decisions might be made by students constructing free-body diagrams, though in many instructional contexts, students have such decisions made for them. In our instructional environment, 
learners are explicitly instructed to make their own reasonable decisions as to what to represent, with the goal being to offer a satisfyingly rich picture of energy dynamics and address any specific questions that may have been raised, while abiding by the constraints of the activity. For example, there are only so many people in the group, so the group needs to find a way to make do with only that number of units of energy.

\section{AFFORDANCES OF ENERGY THEATER FOR LEARNING}

Energy Theater is both a representation (a visual rendering of a scientific phenomenon) and a learning activity (in which participants act jointly to construct scientific ideas). In an earlier publication [4], our focus was on Energy Theater as a representation. In this paper, we focus on Energy Theater as a learning activity: one that is both social (involving the collaboration of multiple participants) and embodied (learners participate with their bodies). The subject of our analysis is learners' embodied collaborations with one another in the material setting that Energy Theater creates. We offer a group of related theoretical perspectives on how Energy Theater promotes collaborative engagement with key conceptual issues in the learning of energy.

\section{A. Embodied interaction}

Our analysis of socially orchestrated action in Energy Theater is informed by a theory of embodied interaction [25]. We adopt a view of the body as a site for the dynamic production of meanings and actions [26,27]. These meanings and actions are produced in multiple interacting and mutually elaborating modalities, including physical orientation, location, gesture, pointing, gaze, talk, prosody, intonation, and tool use [25-29]. For example, in a brief exchange among girls playing hopscotch, when one girl makes a mistake, the second girl communicates the error to her using words, parallel grammatical construction, speech rhythm and intonation, hand gestures, foot stomps, orientation of body and gaze relative to the first girl, and positioning of her body relative to the (interrupted) motion of the first girl [26]. The message is a complex representational entity that relies on the multiple bodily actions from which it is constructed [30].

In earlier publications [3,4], we motivated Energy Theater in terms of a distinct, but compatible theory: embodied cognition in its "conceptualist" sense [27], referring to the theory that humans develop common conceptual systems based on common biologically given bodies and shared recurrent physical experiences. These conceptual systems make themselves apparent linguistically, in the grammar used to speak of abstractions [31-33]. A conceptualist approach to embodied cognition is particularly appropriate to transcript analysis of the sort conducted in our earlier work $[3,4]$. An "interactionist" [27] perspective is better suited to the present analysis, in which video documentation shows participants coconstructing meaning by means of body placement, orientation, gesture, and other bodily actions.

Embodied interaction plays a documented role in learning. Learners in classrooms naturally employ their bodies in the process of making sense of unfamiliar scientific or mathematical phenomena [34-48], particularly when they are asked to share their emerging understanding of events with peers [29,44-48]. Learners' production of gestures may precede their production of technical science words and serve as a developmental stepping stone in the evolution of learners' scientific discourse [47]. These studies primarily investigate situations in which participants use multiple modalities naturally, i.e., without prescription based on an engineered design for learning.

In Energy Theater, instructors deliberately arrange for human bodies, or parts of the body, to stand in symbolically for entities in the description or explanation of a phenomenon. Energy Theater prescribes that certain body actions have certain categories of meaning and broadly promotes the improvised use of those and similar body actions for the social negotiation of meaning. Another example of an embodied learning activity in physics is the application of the right-hand rule for determining the direction of the magnetic force on a moving charge. A variety of other embodied learning activities have been developed in which the body represents mathematical entities [49], molecules [50], electrical charges [51,52], celestial bodies [53-55], computer science entities [56], components of a dynamic system [57,58], cellular processes [59,60], and even literary devices [61].

Embodied learning activities are distinct from "kinesthetic activities," in which the human body is employed as a sensor, e.g., for comparing the physical sensations associated with different forces, pressures, torques, and so on [62-64]. They are also distinct from activities in which students move their bodies for the sake of general physiological stimulation. Though these activities may also enhance learning, we suggest that they do so through mechanisms different from the interactive production of meaning.

\section{B. Learning through participation}

We identify Energy Theater as a social embodied learning activity, meaning that multiple bodies are used symbolically in concert, with the enactment negotiated and interpreted by the community. Because the interpretation of these community acts is often not clear to everyone involved, the establishment of a consensus interpretation for the act is also socially negotiated. To whatever extent each person is invested in a particular proposed global solution to an Energy Theater problem, that person is also invested in persuading others to see the value in the proposed solution, since any global proposal requires others' willful cooperation if it is to be part of the final performance. As when a barbershop quartet sings a chord, 
one participant who makes an unexpected contribution changes the whole result for everyone. The consequence is a high intensity of negotiation of meaning.

A sociocultural perspective informs our understanding of learning as a process of becoming part of a community, as indicated by adopting the language, values, and practices of that community [65]. In this "participationist" point of view, learning is indicated by changes in a person's speech and behavior [66,67]. The learning that Energy Theater promotes is evident for all learners whose talk about energy becomes more aligned with that of disciplinary experts. Learners are not expected to make smooth, linear progress toward expertise; rather, learners are expected to test out words and practices, often using terms and behaviors before they have fully accepted or understood their meaning $[68,69]$. For example, learners who argue about whether it is "electricity," "electrical energy," or "electrons" that travel around an electrical circuit are understood to be learning, since their discussion moves them toward expert use of disciplinary language (whether or not they display canonical usage at the end of a particular episode). How this negotiation unfolds depends significantly on learners' means of interaction with each other and the material setting.

\section{Interaction in a material environment}

The human size of the Energy Theater arena facilitates embodied collaborative work. Each participant has spatial access to the area of the floor in which the energy dynamics are being enacted [70], and everyone has the tools for making proposals visible to themselves and others (bodies and parts of bodies). Particular physical arrangements of people, space, and tools can either promote or hinder particular types of interactions [71,72]. The material environment created in Energy Theater is markedly different from one in which one participant has privileged access to the representation space or the tools for modifying it, such as when one student draws a diagram in her personal notebook with her own pen, or a group of students huddle around a computer screen for which there is only one keyboard [4,46,73,74].

During Energy Theater negotiations, the cognitive demands on the group are numerous. The cognitive work of describing energy transfers and transformations in a physical scenario can be thought of as the process of posing and seeking answers to a set of interrelated questions: What objects have energy at the beginning of the scenario? How much energy does each object have, and in what form? Where does energy go, and how do we know? How much energy ends up in this form, as opposed to that other form? Answering some of these questions requires remembering the answers to other questions, and sometimes reconsidering and revising previous answers. Part of what makes the task manageable is that Energy Theater encodes information about the energy such as "where," "how much," and "what form" in the material structure of the representation; the representation itself "remembers" the group's answers to these questions [75]. The relevant material structure includes how many roped-in regions there are, how many people are standing in each region, and what hand sign each person is making, as well as the facts that people are conserved, each person has a location, and, when counting people, the whole is automatically the sum of the parts. Facts about people and ropes are inherited into the learners' model of energy, so that, for example, units of energy are conserved, located, and easily summed. The energy transfers and transformations can then be negotiated and performed through manipulation of the physical representation. The material arrangement is controlled through physical action in a social context and is thus bound to both embodied interaction and participation.

\section{RESEARCH METHODOLOGY}

In this section we describe our research methodology including our framework for analysis, general methodology, data collection, and episode selection.

\section{A. Framework for analysis}

The increasing ease of video recording offers new opportunities to create richly detailed records of classroom activities. The use of rich records of naturally occurring activities as evidence of learner knowing promotes and supports a sociocultural view, in which learning is a process that shows in what participants do and say together $[66,67]$. For this view of learning, ethnographic perspectives are naturally relevant [76-78]. We identify with the interpretive tradition [79], in which the phenomena of interest for learning are the meaning of activities for the participants. This perspective asserts that participants create meaningful interpretations of physical and behavioral occurrences; that they take action based on their interpretations, i.e., interpretations are causal; and that these interpretations are often invisible to participants, who treat their interpretations as reality [80]. A primary function of the ethnographic researcher in this tradition is to "make the invisible visible" [81]: to describe the implicit social and cultural organization that shapes the participants' activity [82]. For example, a learner may frame an instructional activity as an opportunity for sensemaking or as an assignment to fill out a worksheet $[83,84]$. The learner's framing is implicit, yet it affects what she notices, what knowledge she accesses, and how she thinks to act [85-88].

An ethnographic approach aligns with a particular theory of cause, in which the meanings of activities for participants cause actions, and that causality can be deduced on the basis of an observable sequence of events [89-91]. In this theory, researchers infer cause by observing the processes by which antecedents appear to lead to effects. This perspective contrasts with one in which cause 
is understood in terms of probabilistic relationships between causes and effects [91].

\section{B. Methodology}

We take the perspective that the universal properties of an event or phenomenon emerge from the specifics of a particular case, rather than from the patterns that emerge across cases [79]. In particular, we demonstrate what is universal by identifying what theory the event or phenomenon is a case of and connecting the event to the broader theory. Thus, implicit in our statement that Energy Theater is a case of a social embodied learning activity is the belief that we will discover something universal about social embodied learning activities through careful study of Energy Theater; and implicit in our choice of an Energy Theater episode is the assumption that we will learn something universal about Energy Theater through careful study of that episode.

Interpretive video analysis is the primary means for responding to our two research questions:

- With what specific key conceptual issues of energy do learners engage while doing Energy Theater?

To answer this question, we identify video episodes in which learners engage with energy concepts in general and conduct detailed analysis to characterize the specific concepts with which they engage. We take as a premise that learners' ideas always have some seed of correctness; we attend to that sound thinking both out of respect for the learner as an intelligent person, and because it is the material out of which new growth occurs. We have established interests in episodes that showcase the complexity of elementary physics concepts [92], the correctness and sophistication of learner ideas that can initially appear naïve [93], the meanings and actions produced by the multiple interacting modalities of the body (gesture, gaze, prosody, and so on) [48], and the regularities and expectations for learning that are exposed by being violated [83].

- By what processes does Energy Theater cause learners to engage with those specific conceptual issues?

We respond to this question with interpretive video analysis combined with theoretical study of learning in interaction. We identify episodes in which learners engage with one another as they construct an understanding of energy, and conduct detailed analysis to build plausible causal links between specific features of Energy Theater and the learning events that we observe. In line with our participationist perspective, learning events include those in which learners' talk moves toward expert use of disciplinary language.

\section{Data collection and episode selection}

In what follows, we describe examples of Energy Theater in use by learners in a physics class. The examples show Energy Theater as a learning activity in which participants negotiate a model of energy transfers and transformations for a given physical scenario. The examples are from video records of professional development courses for secondary teachers offered through Seattle Pacific University as part of the Energy Project. In the Energy Project, professional development courses are routinely documented with video, photographs, artifact collection, and field notes. As researcher videographers document a particular course, they take real-time field notes in a cloud-based collaborative document, flagging moments of particular interest and noting questions that arise for them in the moment. Later that same day or the following day, the researcher videographers identify video episodes of interest to share with a research team. We use the term "episode" to refer to a video-recorded stretch of interaction that coheres in some manner that is meaningful to the participants [71]. These episodes are the basis for collaborative analysis, development of research themes, literature searches, and the generation of small or large research projects.

The episodes in this paper were selected from an Energy Theater enactment highlighted by a researcher videographer (author V. J. F.) in the summer of 2011. In this enactment, participants negotiate and perform Energy Theater for an incandescent light bulb. V.J.F. highlighted this particular Energy Theater enactment on the basis of audiovisual clarity, sustained learner engagement with a physical scenario, and appropriate implementation of Energy Theater, i.e., the participants mostly followed the rules specified in Sec. II. The enactment analyzed in this paper is not the only enactment with these features, and we do not present evidence that it is a representative enactment - that is, we do not present evidence that most other enactments have the same features (though our experience suggests that many of them do). Rather, we put forward this enactment as a case of Energy Theater: an instantiation through which we may identify universal features of Energy Theater that are evident in the concrete details of its practice. We expected that this enactment would help us to identify some of the key conceptual issues about energy that learners engage with when doing Energy Theater (our first research question).

After identifying this enactment as one likely to contribute to answering our research questions, the first author (R.E.S.) watched the video multiple times, creating a detailed narrative of events as well as a transcript. On the basis of the narrative, transcript, and multiple viewings, claims were developed that responded to each of the two research questions. Two episodes from within the enactment (described in Secs. V and VI) were isolated and captioned to (1) illustrate learner engagement with the conceptual issues that we identified in response to our first research question and (2) establish within-case connections between specific features of Energy Theater (cause) and engagement with these conceptual issues (effect), as called for by our second research question. These episodes 
appear as Videos 1 and 2. To structure the analysis, these two episodes were further divided into a total of seven "segments," each of which highlights a particular idea being negotiated by the participants. These segments are identified below by a key utterance made within that segment.

\section{DISAMBIGUATING MATTER AND ENERGY}

\section{A. Conceptual foundation: Flows of matter and energy}

Matter and energy are fundamental concepts in the physical sciences, and understanding the dynamics of each is central to the work of science students, teachers, and professional scientists. The Framework for $\mathrm{K}-12$ Science Education [94] states that “...students' abilities to conceive of the interactions of matter and energy are central to their science education." The Framework is organized around scientific practices, crosscutting concepts, and disciplinary core ideas; crosscutting concepts are common to all areas of science and therefore unify the study of STEM fields. The fact that one of the seven crosscutting concepts is "Energy and matter: Flows, cycles, and conservation" demonstrates a consensus in the scientific community that these concepts are both closely related and centrally important.

A functional understanding of matter and energy includes the ability to keep track of transfers into or out of systems of interest and the knowledge that only through such transfers can the total amount of energy or matter in a system be changed. Analysis of a system may require tracking multiple forms of matter (e.g., particular elements or molecules) and of energy (e.g., kinetic, thermal). Availability of particular forms of matter or energy as inputs, and the amount and form of energy and matter outputs, can explain the functioning of a system. This matter-energy model applies to systems in all areas of science; the Framework gives a biological example: "the supply of energy and of each needed chemical element restricts a system's operation-for example, without inputs of energy (sunlight) and matter (carbon dioxide and water), a plant cannot grow" [94]. In this example, as in many systems, a useful analysis of the system requires conceptualizing transfers of both matter and energy.

In many scenarios it is possible to think of matter and energy as moving together from one place to another, for example, when convection currents carry air and thermal energy upward, or when gasoline is transferred into the fuel tank of a car. In other scenarios, however, the direction of energy flow is opposite the direction matter moves, such as in a pulley system used to lift an object, or in some of the phase transitions that take place during the water cycle. Developing a scientific understanding of energy requires differentiating energy from matter, including recognizing that energy dynamics do not uniformly align with matter dynamics $[95,96]$.

\section{B. Embodied action: \\ Distinguishing electrons from electrical energy}

In the pair of episodes analyzed in this section and the next, fourteen participants are outdoors in an open area, where they have laid out loops of colored rope to represent the objects in their scenario of interest: an incandescent bulb burning steadily. In their layout, one large loop of rope represents the outer surface of the bulb, a smaller loop of rope on one side represents the bulb's socket, and a third rope laid down in a curved line within the large loop represents the filament (Fig. 1). This pictorial layout is not the one modeled by instructors, who tend to prefer schematic object areas (loops that bear no visual resemblance to the objects they represent), but is an acceptable and in some ways advantageous alternative. (An advantage for this group is identified in Sec. V B 4 below.) Participants have already negotiated arm movements to represent forms of energy that they term "light, "heat," and "electrical energy." (We discuss some conceptual indications of their labels in Sec. VIB.) Having decided on the objects in their system and the forms of energy that they think are involved in the scenario, the next task is to decide who will go where when: that is, to map out the flow of energy (in its various forms) among the agreed-upon objects [97].

In the episode analyzed in this section, participants attempt to account for the fact that the current is exactly the same before and after the filament, yet some energy leaves the circuit through the filament. The participants recognize this as a case in which they need to carefully disambiguate the "energy story" for the light bulb and the "matter story," and take steps to do so. The episode is about 4 minutes long (Video 1). We analyze three segments from within the episode.

\section{1. "The electron flow is in a circuit."}

At the outset of this episode, Roland takes the position that the group's Energy Theater enactment should include the fact that the flow of electrons is in a loop. In the transcript, the equals sign marks places where a speaker's utterance is continuous even as another speaker also speaks.

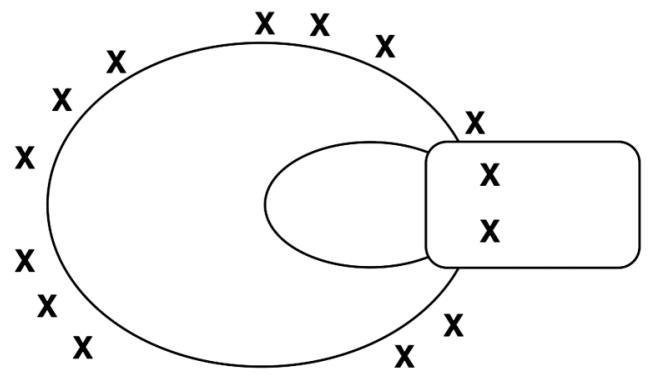

FIG. 1. Initial layout of ropes (lines) and people (Xs) for enactment of Energy Theater for an incandescent bulb. 




VIDEO 1. Participants prepare to enact Energy Theater for an incandescent bulb burning steadily. In this episode, participants attempt to account for the fact that the current is exactly the same before and after the filament, yet some energy leaves the circuit through the filament.

Ted: Why did you say we were going to move?

Roland: Well the whole electron flow is in a circuit. It keeps going around and around. And every time it passes through the filament $=$

Kelli: And some just get taken

Roland: = some of it gets turned into light and heat. I mean that's the simple.

Ted: I guess I'm curi- I mean, aren't we doing like energy though, and not electrons? So it's about transfers and transformations, so we don't-like, I get, you're talking about the matter, but we really care about just the elec- the energy $=$

Roland: Electrical energy

Ted: $=$ transfer and transformation.

Kelli: Does it give off all of the electrical energy?

Toni: No.

Jennifer: As it's passing

Toni: It does not, so you will have energy $=$

Jennifer: Some of it continues around, and just some of it changes into light.

Toni: $=$ still going in a circuit.

[Instructor arrives (author L. S.)]

Jennifer: So even though it's not the electricity there's still electrical energy

Toni: Otherwise you would not have a current any longer.

Jennifer: There's electrical energy leaving the light bulb?

Toni: Yes. There is. Otherwise you would not-you have to have a current! You have to have a flow of electrons those electrons are going to still contain energy.

Pam: But not as much.

Jennifer: So some people will stay electricity the whole time.

Ted: I just think you're talking about matter, or something that isn't energy, and so I don't-I just, it seems to me that it should just be about energy and we should ig- you know, it's about the energy conversions, and to me these diagrams are about the changes in electrical energy and the different types of energy and not necessarily-like what you're saying is we should represent the electrical in, and electrical out, because of electron flow.

Pam: We don't have to use the word electrons. We can just call it energy.

Roland: Electrical energy.

Leah: So Ted are you saying that we shouldn't keep looping is that what you're

Ted: I'm not sure that looping-I'm not sure that the looping is happening, because that's like saying that the, we're going to, I don't know-Are we saying that electrical energy is going to come in, and then come back out unchanged?

(Many at once): No, no, no!

Toni: Some of it, yes!

In the above conversation, Ted expresses his concern that Roland, and perhaps other members of the group, are representing the flow of matter in the light bulb when they ought to be representing the flow of energy. He initially asks, "Aren't we doing energy though, and not electrons?" and later states, "I just think you're talking about matter, or something that isn't energy ... it should be just about energy." Ted seems to be asking the group to consider the possibility that although the electrons may go around the circuit in a loop, the energy does not ("I'm not sure that the looping is happening"), so they should not themselves "keep going around and around" as Roland had initially suggested. Toni states that the flow around the circuit is an energy flow, not (or not only) a matter flow, because the electrons that flow around the circuit "still contain energy." Thus, she claims, "you will have energy still going in a circuit."

Ted's concern that the electrons be distinguished from the electrical energy is a valid one. Energy Theater is a representation of energy, and the movement of energy through a system is not determined by the movement of material objects in the system. For example, in an Atwood's machine, we model the energy flow as being against the motion of the string over the pulley: the work by the string on each mass is negative and positive, respectively, as though the string were removing energy from the falling mass and giving it to the rising mass. The contrast between the movement of objects and the movement of energy can be counterintuitive. Learners new to Energy Theater sometimes mistakenly represent the movement of objects instead of energy [98]. Some participants in this group use language that blends energy with material objects: Jennifer uses the term "electricity," which could refer to either electrons or their energy, and Pam suggests that if Ted is uncomfortable talking about electrons "we can just call it energy" instead.

Toni's argument that the electrons flow together with the energy seems to go against Ted's wish to treat them as 
separate entities. Yet her argument is also valid: Electrons have energy, and if electrons go in a loop, so does the energy associated with them. Toni speaks loudly in this part of the discussion and overlaps other participants, suggesting that it is important to her that this fact be included in their representation. The importance seems to stem at least partly from a wish to show that current flows out of the bulb as well as into it: she states, "otherwise you would not have a current any longer." The fact that current is not used up by a light bulb is counterintuitive to many learners [99-102]. Later in the discussion (just after the end of Video 1), some participants in this group express surprise that current flows out of the bulb as well as in, along with concern for their students' understanding:

Jennifer: I think what we have to get past I think many of our students are going to think this way like, electricity, comes from the plug and it goes out, it just keeps coming out from,

Drew: That it's a one-way.

Jennifer: Yeah

Leah: Yeah, good point.

Jennifer: And you're saying, and I never really thought about it very much, I haven't studied it much but you're saying that's not true, it goes back out as well.

Toni: Some of it.

The idea that current is used up by a light bulb is traditionally understood by educators as a detrimental misconception [99-102]. Toni's vehemence may indicate a wish to protect her colleagues and their students from using Energy Theater to support an incorrect current model.

Energy Theater, like any representation, foregrounds some features of a physical phenomenon and deemphasizes others. While a correct Energy Theater representation need not show the conservation of electron current any more than a correct free-body diagram needs to show the velocity of an object, the fact that current is conserved in a light bulb is important to understanding its operation. As the participants consider their options in representing the first steps of the energy dynamics, they work to reconcile their model for energy with their model for current. This reconciliation produces several significant, difficult physics questions. By what means does energy enter (and possibly exit) the light bulb? The current appears as the natural culprit. However, the concept of current conservation states that the current is the same quantity when it leaves the bulb as when it entered. How can the current be the same, yet have less energy? Why does an electric circuit require a return of the current to the battery when energy is transformed in the light bulb? These questions are highly nontrivial, have been tackled by physics luminaries such as Feynman and Sommerfeld, and still arouse interest in the literature [103-105]. Our instructional perspective on these questions is that electric circuits provide an excellent context for disciplined model-based reasoning. Physics nuances raised by a specific group of learners may be pursued to further clarify and refine the questions being asked.

\section{2. "Some of us turn into light and heat as we go around the loop."}

In a subsequent section of the conversation, the participants devise a model that includes both the transformation of electrical energy into other forms and the persistence of current through the filament. In the proposed model, an electron is represented by a group of three units of energy, e.g., three people who travel in a group. These three people are initially all in the form of electrical energy; as they pass through the filament, two of the three transform into two other forms of energy, which these participants call light and heat. (Again, we defer discussion of these terms until a later section, in which the participants give more evidence of what they mean by these terms.) Ted is "not convinced."

Kelli: Three could come in and two is going to change to heat and light and one's going to continue around. Then three more is going to come in and they'reThat's my picture.

Toni: Yep

Ted: I'm just not sure why you guys are saying that. To me I'm not convinced.

Bahia: We have to decide what we are going to cover, electrons, or electrical energy.

Roland: Well let me see if I can handle this. So if I'm the electric energy, the current, I'm going in, here's the filament, some of us go to light and heat, right? I mean, we all go, keep looping but we have to somehow display how some of us [bangs self], some of me, turns into light and heat as we go around this loop.

Drew: Ted would it help and I'm, I need clarification I'm not sure if this is correct, would we say, Toni, that electrons that are electrical energy that are not being transformed into heat and light, and they're returning, quote-quote "to complete the circuit," would they have electrical potential energy?

Toni: They still do otherwise you couldn't have a string of Christmas lights.

Drew: So maybe that helps, is that we're not so much tracking an electron as a function of being a form of matter, but we really need that in the equation because we have this idea we've got electricity in the form of electrical potential energy going back. So to make a complete picture maybe, Ted, we need to include it.

Toni: So if you look, if we have an electron it would be us, packets of energy

Leah: Yeah yeah yeah

Toni: Okay. And the electron follows the circuit, Roland you're going to be the energy that remains and comes 
back out. And some of that energy will go off as heat, some of it will go off as light, some of it continues on back. Because that electron is still moving.

Ted: This isn't about matter electrons.

Toni: No, that's what electrical potential is. You gotta remember, if that electron cannot move, you do not have, it transfers its electrical potential by motion. So what we were, were not electrons, we were the packets of energy in an electron. Two of us went off, one continued on.

Kelli initially makes her suggestion verbally. Roland repeats the proposal physically, by walking around the representation space while he explains the idea. While saying, "Well let me see if I can handle this," he walks from his starting position (which happens to be in the socket) out into the middle of the large ring formed by the participants. While saying, "If I'm the electric energy, the current, I'm going in, here's the filament," he turns his course and walks back toward his starting point, presumably following the line of the filament laid out on the ground. By the time he says, "Some of us go to light and heat," he has returned to his starting position. With "Right? We all, go, keep looping but," he walks back out into the middle of the ring again and pats his abdomen repeatedly with both hands. As he continues with "We have to somehow display," he waves his hands outward high above his head, as though throwing or pushing something away from himself; he repeats this "display" gesture as he rounds the corner of the filament again. On the way back to his starting point, as he says "how some of $u s$," he smacks his chest twice with both hands, hard enough to make a sound that is audible even though he is not wearing the microphone. Finally, while saying "or some of me, turns into light and heat," his arms hang loosely, and he returns to his place in the circle.

Recapping the action briefly: Roland walks around the loop of current twice as he explains the idea proposed by Kelli. The first time around, he simply walks as he talks. The second time around, he gestures both (1) outward (the display gestures) and (2) onto his own body (patting his abdomen and banging his chest). Our interpretation of Roland's behavior is that he is attempting to simultaneously model (1) the outward movement or display of something and (2) the persistence of something around the whole circuit. In representing this complex situation, Roland uses not only words, but also body movement and gesture, making use of the material structure of the representation space [26] in a one-man version of Energy Theater. Roland's explicit identification with the energy"some of $m e$ "-may be an example of the blending of personal identity with physics entities for the purpose of problem solving [106].

Drew asks a question of Toni (roughly, would the returning electrons have electrical potential energy?), and in response, Toni not only offers evidence verbally in support of her claim ("Otherwise we couldn't have a string of Christmas lights") but walks across the circle to stand next to Roland. While Drew makes his statement about the "complete picture," Toni grabs Roland by the upper arm with her right hand and Pam by the upper arm with her left hand, and pulls them to stand close to and a little bit in front of her. When Drew is finished talking, Toni says, "If you had an electron it would be us, packets of energy," pushing first Roland and then Pam out in front of her and walking along behind them on the same path that Roland had taken previously. Roland walks ahead around the path, waving his arms in an approximation of the sign agreed upon for electrical energy; behind him, Toni pushes Pam partway around the path, then guides Pam to leave the path, so that she ends up facing outward from the circle of participants. Toni continues along the path as she says, "And the electron follows the circuit. Roland you're going to be the energy that remains and comes back out." She then leaves the path herself and faces partly outward from the circle of participants, twisting her upper body back to the middle to summarize: "Some of that energy will go off as heat, some of it will go off as light, some of it continues on back." Figure 2 illustrates this "electron" model.

Energy Theater enables participants to enact proposals during the collective negotiation of the energy dynamics. Roland and Toni engage in dramatic embodied action, using their own and others' bodily placement, motion, gestures, and so on to create and express their ideas about energy. Roland simultaneously walks and gestures to model the outward movement of energy along with the persistence of current around the circuit. Toni grabs two other participants to physically recruit them into her enacted model of an electron as a packet of three energy units that travel together, then transform and separate.

\section{3. "We're solving the matter-energy problem."}

A bit later in the discussion (three minutes after the end of the episode in Video 1), Leah proposes a means to "solve the matter-energy problem," as she puts it. She suggests that the three people representing an electron's energy carry a rope around themselves, to remind viewers that they, as usual in Energy Theater, are units of energy within a material object.

Leah: Would it help to think of like we're three packets of energy in a little rope and we're carrying the rope through as the electron, and some of us are leaving this little rope that we're carrying around? Would that solve the-You know what I mean? There's three of us and a little rope we're carrying with us, into the filament, and then we leave the little rope, like some of us turn into heat, some turn into light, and then the person with the rope keeps coming back through here. 


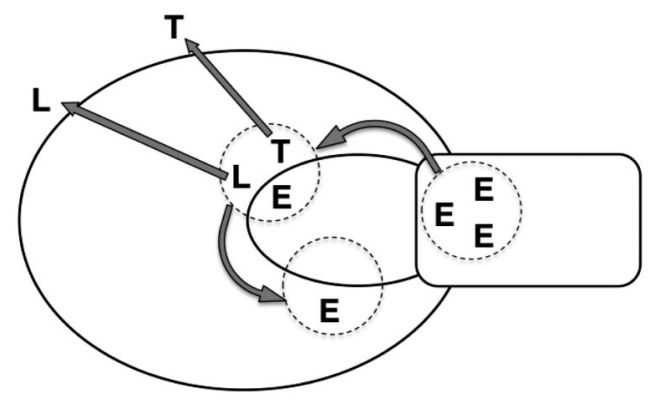

FIG. 2. "Electron" model of energy dynamics for an incandescent bulb burning steadily. E, T, and L represent electrical, thermal, and light energy, respectively. The dashed circle denotes an electron.

Drew: The rope would represent

Leah: An electron.

Drew: Oh an electron

Leah: So then we're solving the matter problem, the matter-energy problem.

Drew: You would still be the energy packet that's at a lower energy level.

Leah: I mean I don't know. I don't care but I'm just thinking about your, the matter-energy problem.

Toni: You know the little demo we did with the three of us, we weren't representing the matter at all, that's the confusing part.

Leah: True

Toni: And because you still have energy maintained in the matter, we're getting hung up on the matter representation, and what we did was pure energy. Not all the potential is realized.

Leah's idea stretches the rules of Energy Theater in that normally ropes do not move. Motion of objects is supposed to be indicated by including kinetic energy in the area designated for that object, not by displacing the rope that bounds the object area within the representation space. However, in another way, Leah's idea is an insightful application of the rules of Energy Theater. Leah proposes to mark the three people doing the walking as units of energy in the electron by surrounding them with a rope, thus designating them, in the normal Energy Theater manner, as energy contained in a specific object. Without Leah's rope, the energy units would be properly interpreted to be contained in the light bulb (given where the people involved are standing). Leah's rope further specifies that these energy units are in an electron (which is itself in the light bulb).

Leah's suggestion might be helpful for clarifying that the people in the Energy Theater arena represent energy, not electrons. However, her idea is not physically enacted by the group. In response to Leah's proposal, Toni acknowledges potential confusion due to the "matterenergy problem," but insists that her representation is "pure energy."

\section{Learning through participation, embodiment, and the material setting}

This episode shows how Energy Theater promotes conceptual learning about energy through participation, embodiment, and the material setting. Energy Theater-a material representation that uses the metaphor of energy as a substance-contributes to the disambiguation of matter and energy for these participants. The Energy Theater representation encodes a distinction between material objects and energy: energy (represented by participants) is located in objects (represented by areas demarcated by loops of rope). The energy in a scenario is clearly distinct from the objects (i.e., participants stand within, but are not mistaken for, areas inside loops of rope). At the beginning of the episode, many participants were treating matter and energy interchangeably. The activity of developing an Energy Theater enactment for this scenario caused the group to grapple with the distinctions between matter and energy, and to invent enactments that illustrated these distinctions.

The materially structured environment of Energy Theater enforces the constraints of the energy model, "remembering" certain facts about energy and shaping the group's insights as they work together. The fact that energy is conserved, and thus can be tracked as it moves among the objects in the scenario, is built into the material setting in that energy units are represented by durable objects (people) that move among marked areas on the floor (objects). The fact that not only energy units, but also electrons, move among the objects in the scenario (filament, bulb, etc.) is made salient by the physical layout of people and ropes in the shape of a light bulb. The multiple, interacting constraints of the model are made tractable by the stability of the physical arrangement: The ropes, once laid out, remain there until they are rearranged, and the people remain in existence, though their location can change. Thus the stability of the learners' model of energy in this scenario is coupled to the stability of the material world [92]. Partly as a result of this stability, learners face the complex question of: Is the movement of energy the same as the movement of electrons, or is it different? The fact that learners have arranged the ropes specifically in the form of a light bulb provides some tools for them to pose this question: it helps them ask, Does the energy go in and come out at the same physical locations as the current does, and in related amounts, or is it a whole different flow than the current? Learners negotiate their answers to these ideas partly by negotiating the material environment and the things in it, including each other. Though the rules of Energy Theater alone might also support a detailed energy analysis (one might be able to do it "in one's head"), we suggest that the absence of material structure would make such an analysis significantly more difficult.

Interactional as well as material affordances of Energy Theater contribute to the group disambiguating matter and 
energy in this episode. Ted, Toni, Kelli, Roland, and Leah engage most visibly in the collective endeavor of sensemaking that characterizes learning through participation. Ted and Toni use claims and evidence to engage in argumentation with each other and with other participants. Roland and Toni physically enact proposals. Kelli verbalizes an idea for unifying their perspectives by representing both the persistence of electric current and the dissipation of energy. Leah suggests a consensus-building physical enactment involving carrying a rope. Various other participants make moves to add to the argumentation, persuasion, and negotiation that move the group forward.

Embodiment, participation, and the material setting interact in Energy Theater to create a situated, distributed understanding of energy flows in a light bulb for the participants. These learning affordances push participants to engage with key conceptual issues in energy learning, in this case the disambiguation of energy and matter.

\section{THEORIZING MECHANISMS OF ENERGY TRANSFORMATION}

\section{A. Conceptual foundation: Theorizing mechanisms for energy processes}

The pursuit of causal mechanistic explanations is central to scientific analysis. The Framework for K-12 Science Education states that "many of the most compelling and productive questions in science are about why or how something happens" [94]. Others have argued that the pursuit of coherent, mechanistic accounts of natural phenomena is central to scientific inquiry [107-110]. Analyses of energy dynamics can seem to sidestep questions of mechanism when energy is understood as a pure numerical quantity, "not a description of a mechanism" for a physical process [111]. Nonetheless, if (say) kinetic energy transfers from one object to another, our explanation of the energy dynamics needs to include some mechanism by which that transfer took place-perhaps a collision in which mechanical work was done. If kinetic energy transforms to thermal energy within an object, our explanation needs to identify a dissipative process by which that transformation occurs.

Though national standards and disciplinary norms assert that energy is a unitary physical quantity, they also organize the experience of energy into categories according to how it is detected $[94,96,112]$. In particular, "forms" of energy are associated with specific observable and changeable properties of objects [113]. In line with these norms, we take the position that transformations of energy from one form to another constitute physics phenomena appropriate for learner analysis. Energy Theater includes energy transformation, and thus models energy as having various forms. In what follows, we present an episode in which learners theorize mechanisms of energy transformation. This particular episode does not include discussion of mechanisms of energy transfer.
Thus far, we have made the case that Energy Theater promotes the disambiguation of matter and energy. In what follows, we describe another affordance of Energy Theater, which is to prompt learners to theorize about mechanisms by which energy changes form (e.g., from electrical to thermal). Energy Theater supports learners in theorizing mechanisms of energy transformation even though such mechanisms are not an explicit part of the representation [114]. In Energy Theater, forms are labels for units of energy (e.g., hand signs for each person) and changes of form are visible events (one or more people changes hand sign). In the episode below, learners who decide to change (or sustain) their forms are called upon to account for their decisions in terms of causal mechanisms for energy transformations. Further, some questions of mechanism are closely tied to questions of time ordering; Energy Theater represents the time order of transformations, and thus may prompt questions about mechanism. In the episode below, learners struggle over whether light energy is created before, after, or simultaneously with thermal energy in an incandescent light bulb, and thus whether the light is caused by the hotness or vice versa. Energy Theater equally supports theorizing mechanisms for energy transfer from object to object, but the data below do not bear on that claim.

\section{B. Embodied action: Theories of energy transformation in incandescence}

The episode we will examine below is from the same Energy Theater enactment as the previous episode (modeling the energy transfers and transformations in an incandescent bulb burning steadily), but occurs a few minutes later. In this part of the conversation, participants discuss whether heat and light are both made from electrical energy in the filament, or whether one is made from the other. The discussion raises questions of how a specific form of energy may be transformed into another form, and what the limitations may be on such transformations. The question of what transformations are physically allowable also prompts the participants to better articulate what they understand heat and light to be. We analyze four segments from within the four-minute episode (Video 2).

\section{1. "Did we decide if we're going to convert the electrical to light and then heat, or do them both at the same time?"}

Mechanisms of energy transformation are not explicitly represented in Energy Theater, but frequently arise for discussion because other features of the representation raise questions of mechanism. In the case of the light bulb scenario, participants are driven to consider mechanisms of energy transformation as part of deciding on the time ordering of the transformations. Ted is the first to raise the question of whether electrical energy transforms simultaneously to heat and light, or first to one and then the other: 


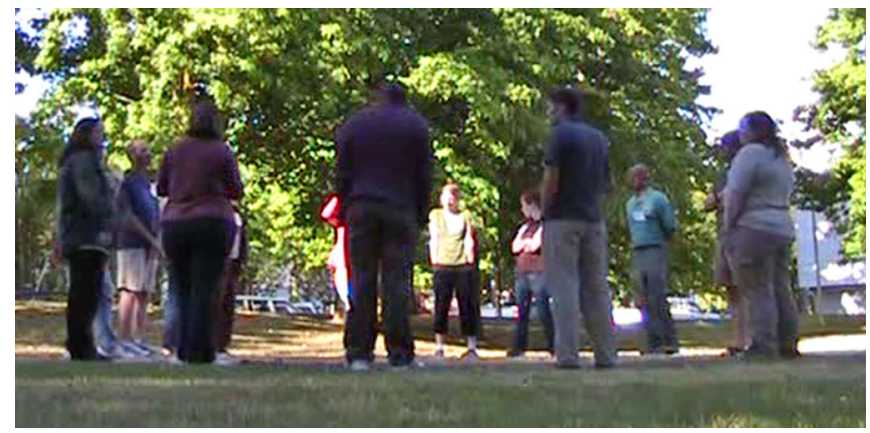

VIDEO 2. Participants prepare to enact Energy Theater for an incandescent bulb burning steadily. In this episode, participants discuss how a specific form of energy may be transformed into another form, and what the limitations may be on such transformations.

Ted: Did we decide if we're going to convert the electrical to light and then heat, or do them both at the same time, because that's still kind of unresolved for me.

Roland: Well the light's going to go first, and then, when it hits the bulb, it turns into heat.

Kelli: I think we should do every other person, like one person comes in and changes to light, the next person comes in and changes to heat.

Ted articulates two options for enacting the scenario. The first is that electrical energy may turn first to light, then to heat. Roland may be aligning himself with this option when he says that "light's going to go first." Ted's second option is that electrical energy may turn to light and heat simultaneously in the filament. Kelli appears to be supporting this option with her suggestion that units of electrical energy should alternate transforming into light and heat as they pass through the filament.

Roland further states that heat is generated when it hits the bulb (by which we speculate that he means the glass enclosure). Roland's suggestion offers a hint of what he may mean by the term heat: heat is a form of energy that appears when light energy impinges on a material object ("the bulb"). An association of heat with the temperature of an object is common in everyday speech, in nonphysics textbooks, and in standards documents $[1,115]$, but is not aligned with disciplinary norms in physics, in which the energy associated with temperature is often termed "thermal energy" and the term heat refers to energy transfer from a body at higher temperature to one at lower temperature. There is no indication that any participant in either episode uses the term heat to refer to energy transfer. Rather, all participants speak of heat as being a form of energy. Ted and Kelli, for example, each speak of converting other forms of energy to heat, and various participants use a fanning motion to indicate their form of energy as heat.

Energy Theater supports participants in distinguishing energy forms from energy transfers in that each of these options has a distinct representation in Energy Theater. For example, energy in the filament is represented by people standing in the area representing the filament; transfer of energy through the volume enclosed in the bulb is represented by people walking through the area representing that volume. Because these two quantities are represented differently, we need not depend on proper use of technical terms for evidence of learner understanding. Instead, we accept that in this local context, the term heat refers to a form of energy associated with temperature. The instructor, who is present for the whole episode, elects not to correct this misuse of a technical term, consistent with our understanding that preventing the incorrect use of the term heat might detract from the primary goal of this learning activity (to map the flow of energy in its various forms among the relevant objects).

\section{2. "The filament heats up first, and then there is light."}

In response to the above exchange, Pam makes a proposal that refers to her understanding of how light bulbs work: she proposes that the heat is created on the filament (rather than on the glass enclosure of the bulb, as Roland had suggested), and that the light is created after that. In this short discussion, the participants use the term heat partly in a colloquial sense (the filament "heats up," interchangeable with "warms up") and partly in a sense equivalent to what physicists call thermal energy ("heat is created on the filament").

Pam: Isn't the heat created on the filament?

Ted: That's what I'm, I'm not sure. Does the heat happen at the same time as the light? You know, does the filament heat up,

Multiple speakers: Yes

Pam: The filament heats up first, and then there is light.

Ted: Boom, concurrently,

Drew: This has already been warmed up. This is steady state.

Kelli: It's already been warmed up but he's talking about the actual energy. Is it turning into one and then the other.

Leah: Right.

Ted initially reiterates that he is not sure about the temporal sequencing, asking if the heat and light happen at the same time. During and after his question, various participants say "Yes" one after the other, but it's not clear whether they are responding to him or to Pam. Drew's reiteration that "this is steady state" may be in response to either Ted or Pam, but in either case highlights an ambiguity in Ted's question: Is Ted asking about the sequence of physical changes as a light bulb comes on, or is he asking about the sequence of energy processes when the light bulb is operating at a steady state? Kelli seems to perceive the same ambiguity and asserts that Ted is asking about the sequence of energy processes. 
The instructor for the course, author Lane Seeley, is present for this part of the conversation. Lane has been listening without speaking for several minutes (since early in the episode analyzed in Sec. V). Lane infers that Ted's question is important to Ted partly because the temporal ordering of the sequence of energy processes has implications for an underlying chain of causality. He answers Ted's question, and answers in the language of causality, not temporal ordering. Leah, Ted, and Pam all appear to accept Lane's statement as answering Ted's question.

Lane: My model is that light, that with incandescent bulbs, the light, the filament glows because it is hot. Leah: Right.

Ted: So heat, light.

[4 second pause]

Pam: Amen.

Lane has made the first explicit statement of the mechanism of energy transformation in a light bulb: "The filament glows because it is hot." This statement defines incandescence (in which bodies emit visible electromagnetic radiation as a result of their temperature). It also embeds the answer to the question the group has been considering, without telling them what to do in so many words: If the filament glows because it is hot, then the light is a result of the hotness, and therefore happens later in the process of incandescence. In other words, in the filament, electrical energy is transformed into what we would call thermal energy (what the group calls heat), and then that thermal energy is transformed into light. The learners' recognition of Lane's statement as an answer to Ted's question suggests that at least some of the learners already understood the question to have been implicitly about mechanism.

In this episode, Energy Theater fosters discussion of causal mechanism in physical processes, which is a hallmark of scientific reasoning $[94,107,108]$. Thinking about causal mechanism occurs by means of thinking about the sequence of energy processes that Energy Theater explicitly represents. In incandescence, the association between sequence and causation is a productive one. In other scenarios, where the association is less clearly productive, we still see learners identifying energy processes with causal mechanism. For example, when a car speeds up on a highway, the pavement plays an essential role in the physical mechanism by which the car moves forward (it exerts a force on the car) but a subtler role in the sequence of energy processes (does the chemical energy in the fuel pass through the pavement before becoming motion energy in the car?). Our observation that many Energy Theater participants want to track the energy through the pavement suggests that Energy Theater strongly supports the association of energy processes with causal mechanisms. In other words, Energy Theater naturally pushes learners to construct not only what is happening but also why it is happening.

\section{3. "We're not saying heat is turning into light; that's physically impossible."}

Even though the heat causes light model is endorsed by the instructor, Toni objects to it. Her objection offers insight into what she understands by the terms heat and light, and lays out specific constraints that she believes limit energy transformations.

Toni: I have a problem with the heat-to-light because light's a higher energy state than heat.

Roland: It's going to light up first.

Ted: The filament's going to heat up to emit light.

Pam: But the heat is first. You can tell when you turn a light bulb off.

Toni: But we're not saying heat is turning into light; that's physically impossible.

Roland: Yeah. The other way.

Pam: Okay so some electrons turn to heat some turn into light?

Toni: You go to heat $=$

Ted: So you have to have heat energy and then you get the light.

Toni: $=$ or you go to light. Yeah. Yeah.

Ted: And then the heat tran- we continue to create heat and light, and they transfer to the outside.

Toni: Yep. The heat doesn't turn into light.

Toni's objection to Pam and Lane's model is a broad one: she claims that "light's a higher energy state than heat," and that it is therefore "physically impossible" for heat energy to transform into light energy. Toni suggests that the correct representation of incandescence will show some electrical energy turning to heat (possibly first), and some electrical energy to light, but not show electrical energy turning into heat that then turns into light. Pam begins to make an argument that "the heat is first," citing as evidence that "you can tell when you turn a light bulb off." She may be referring to the fact that a bulb can be warm, though dark. Another possibility is that Pam is referring to an afterglow of a filament after the electrical switch is turned off: if the electrical energy is no longer getting to the filament but the filament is still glowing, then it must be the heat (thermal energy) of the filament that is causing the glow. Pam does not elaborate further in this moment, and the group makes an effort to adopt Toni's suggestion.

In her statements, Toni describes light and heat as being energy states, of which light is a higher one than heat. In describing energy this way, Toni makes use of a metaphor in which types of energy form an ordered set of vertical locations [3]. Toni's move is a departure from the Energy Theater representation, which uses a substance metaphor. However, Toni's assertions are related to a canonical disciplinary understanding of the energies involved in incandescence. Suppose for the moment that by "heat energy" she means something akin to "thermal energy," 
an association that is plausible in the conversation so far. Material substances can be warm to the touch (conduct thermal energy), but do not glow visibly (emit visible light energy) below a temperature of about $800 \mathrm{~K}$. The condition in which the filament is merely warm is a lowertemperature condition than the condition in which the filament glows; and since temperature, in this context, is associated with energy, perhaps it is reasonable to associate warmness with a lower energy state than brightness. However, the conclusion that Toni reaches-that heat (thermal) energy cannot transform into light energy-is inconsistent with the phenomenon of incandescence.

\section{4. "The way we define light is wavelengths with higher energy."}

The instructor interrupts the group's efforts to ask Toni to elaborate on her assertions. Toni's response associates each form of energy with a wavelength.

Lane: What do you mean that's physically impossible? I've never heard that.

Toni: Heat energy, the wavelength gaining energy.

Pam: But it builds up.

Toni: Because isn't heat our dead end?

Lane: Um, no, I don't think so. Because I can get out an infrared camera and I can look at all of you with an infrared camera and I can actually see infrared, which is another form of light coming from you, and the reason I can see that is because you're warmer.

Toni: But the way we define light is wavelengths with higher energy. When we say light we're talking about visible light. We're not talking about all of the electromagnetic spectrum, yeah. And when we say heat, we're actually talking about thermal energy, it's lower energy, wavelength, longer wavelength. To my knowledge, what takes that longer wavelength is due to what? The buildup of the electrons on the filament.

Lane: So I don't have a wavelength-I don't have a way of associating a wavelength with the thermal energy, which is just the rattling around of the stuff, in this case it's tungsten, that's just microscopic motion, of actual physical atoms.

Toni: But I'm saying when that energy is transferred to the environment it doesn't suddenly speed up so now it's visible to us. That packet of energy.

Pam: I thought it did.

Lane: How did you see it?

Toni: Because that's a different packet of energy.

Leah: That light energy comes from electrical.

Toni: Two separate packets of energy.

Toni's elaboration suggests at least two distinct possible interpretations of her statement that "heat cannot turn into light." One possibility is that she is saying that thermal energy is infrared light energy and cannot transform into visible light energy. This interpretation fits with her statement about "the wavelength gaining energy," and with the sense that examples of infrared light transforming into visible light are uncommon. Another possibility is that Toni is saying that thermal energy associated with matter cannot transform into visible light energy. This second interpretation is suggested by Toni saying, "when that energy is transferred to the environment it doesn't suddenly speed up so now it's visible to us"; the speed of light is greater than any speeds associated with the thermal motion of matter in a light bulb filament. Both of these possibilities are distinct from the model of incandescence that might have been suggested by Toni's earlier statements (Sec. VI B 3). In any case, Toni's argument is influential: in the rest of this discussion, this group of learners goes on to articulate more details of the electron model.

\section{Learning through embodiment, participation, and the material setting}

This episode shows further how Energy Theater promotes conceptual learning about energy through embodiment, participation, and the material setting. Ted's opening question, about the time ordering of energy transformations, is a question that the group must answer in order to enact the sequence of energy transformations with their bodies. Kelli proposes a response in terms of human bodies ("I think we should do every other person"). The negotiation as to whether the bulb is heating up or burning steadily is supported by the fact that in Energy Theater, the sequence of physical events (e.g., the bulb getting warmer and warmer) is represented in a way that is distinct from the sequence of energy processes (e.g., the electrical energy turning to heat and light): the former is represented not by bodily movements, but by using different "acts" of Energy Theater (in the sense of the main divisions of a theatrical performance). Thus, embodied action and the material structure of Energy Theater continue to shape the discussion [116].

The participation in this episode is notable in that learners engage in a complex and productive discussion of mechanisms of energy transformation. Their collective endeavor of sense making includes a complex sequence of claims and counterclaims based in abstract principles ("light's a higher energy state than heat"), direct experience ("you can tell when you turn a light bulb off"), microscopic models ("doesn't suddenly speed up so now it's visible"), and presumed causal relationships ("the filament's going to heat up to emit light"). Their argumentation, persuasion, and negotiation advance their construction of energy models for incandescence.

The group's intellectual work in this episode is incomplete in some senses, and flawed in others. The electron model is not as accurate as the heat causes light model (for incandescence; the former might be more appropriate for 
fluorescence). They run out of time to decide between their models. They misuse the term heat in a variety of ways that may muddle their reasoning. Toni's peers may hesitate to critique her logic in light of her loud and assertive tone. Overall, though, we see the group as making a significant achievement in this episode: They construct two distinct, sophisticated, and plausible models for energy dynamics in a glowing filament (the electron model and the heat causes light model). Each of these models conserves and tracks energy as it transfers among and transforms within the relevant objects in the system of interest.

\section{SUMMARY}

We describe examples of a social embodied learning activity called Energy Theater in use by secondary teachers learning physics in summer professional development courses. Energy Theater is designed to support learners in conserving energy as they track energy transfers and transformations within, into, or out of the system of interest in complex physical scenarios. Our analysis of two episodes in which participants model the energy dynamics of an incandescent bulb provides a response to our first research question: While doing Energy Theater for this specific scenario, learner engagement with key conceptual issues of energy includes (1) disambiguation of matter and energy and (2) theorizing mechanisms of energy transformation. We expect that other scenarios would promote engagement with both these and other conceptual issues. We suggest that Energy Theater and its associated representations [4] may provide a generative basis for energy instruction for a variety of different learning populations.

Our second research question concerns the processes by which Energy Theater causes learners to engage with those conceptual issues. We identify causal processes by observing specific sequences of events in enough detail to establish a likely causal relationship between specific features of Energy Theater and the conceptual engagement that we see take place. In the episodes analyzed, disambiguation of matter and energy appears to be promoted especially by the material structure of the Energy Theater environment; since energy is represented by participants, while objects are represented by areas demarcated by loops of rope, learners must distinguish the two in their Energy Theater enactment. Theorizing mechanisms of energy transformation is supported especially by Energy Theater's embodied action; this necessitates modeling the time ordering of the transformations, leading to discussions of the possible causes of different time orderings. Broadly speaking, we attribute the effectiveness of Energy Theater to the interactional affordances of learners' embodied collaborations with one another in the material setting that Energy Theater creates.

Our analysis has theoretical and methodological implications. A participationist theory of learning, in which learning is indicated by changes in speech and behavior, supports ethnographic analysis of learners' embodied interaction with each other and the material setting. (This approach contrasts with theories in which learning is knowledge acquisition, measured by comparison of knowledge states at two points in time.) We suggest that these learning theories and analytic methods are useful for examining the learning activities that we create and sustain in physics classrooms.

\section{ACKNOWLEDGMENTS}

We gratefully acknowledge all the elementary and secondary teachers who have participated in Energy Project courses for their generosity in making their own and their students' reasoning accessible to the Energy Project team. We are indebted to all the members of the Physics Education Research Group at Seattle Pacific University, especially Lezlie S. DeWater, Abigail R. Daane, and Kara Gray, for ongoing development and critical feedback. We also thank the national community of Energy Project collaborators for their engagement with our work, particularly Leslie J. Atkins, Benedikt Harrer, and Jim Minstrell. This material is based upon work supported by the National Science Foundation under Grants No. 0822342 and No. 0962805.
[1] P. A. Kraus and S. Vokos, The role of language in the teaching of energy: The case of heat energy, Washington State Teach. Assoc. J. (2011), http://www.spu.edu/depts/ physics/documents/WSTA_KrausVokos.pdf.

[2] B. W. Dreyfus, E. F. Redish, and J. W. Watkins, Students' views of macroscopic and microscopic energy in physics and biology, AIP Conf. Proc. 1413, 179 (2012).

[3] R. E. Scherr, H. G. Close, S. B. McKagan, and S. Vokos, Representing energy. I. Representing a substance ontology for energy, Phys. Rev. ST Phys. Educ. Res. 8, 020114 (2012).
[4] R. E. Scherr, H. G. Close, E. W. Close, and S. Vokos, Representing energy. II. Energy tracking representations, Phys. Rev. ST Phys. Educ. Res. 8, 020115 (2012).

[5] H. G. Close, L. S. DeWater, E. W. Close, R. E. Scherr, and S. B. McKagan, Using The Algebra Project method to regiment discourse in an energy course for teachers, AIP Conf. Proc. 1289, 9 (2010).

[6] E. W. Close, R. E. Scherr, H. G. Close, and S. B. McKagan, Development of proximal formative assessment skills in video-based teacher professional development, AIP Conf. Proc. 1413, 19 (2012). 
[7] H. G. Close and R.E. Scherr, Differentiation of energy concepts through speech and gesture in interaction, AIP Conf. Proc. 1413, 151 (2012).

[8] S. B. McKagan, R. E. Scherr, E. W. Close, and H. G. Close, Criteria for creating and categorizing forms of energy, AIP Conf. Proc. 1413, 279 (2012).

[9] B. W. Harrer, R. E. Scherr, M. C. Wittmann, H. G. Close, and B.W. Frank, Elements of formative assessment in learners' discourse about energy, AIP Conf. Proc. 1413, 203 (2012).

[10] A. R. Daane, S. Vokos, and R.E. Scherr, Conserving energy in physics and society: Creating an integrated model of energy and the second law of thermodynamics, AIP Conf. Proc. 1513, 114 (2013).

[11] L. C. McDermott and L. S. DeWater, The need for special science courses for teachers: Two perspectives, in Inquiring into Inquiry Learning and Teaching in Science, edited by J. Minstrell and E. van Zee (AAAS, Washington, DC, 2000), http://www.aaas.org/programs/ education/about_ehr/pubs/inquiry.shtml.

[12] P.S. Shaffer and L. C. McDermott, A research-based approach to improving student understanding of the vector nature of kinematical concepts, Am. J. Phys. 73, 921 (2005).

[13] L. C. McDermott, P. S. Shaffer, and C.P. Constantinou, Preparing teachers to teach physics and physical science by inquiry, Phys. Educ. 35, 411 (2000).

[14] For our view of the analogy between energy and money, see Ref. [4].

[15] R. E. Scherr, A. R. Daane, and S. Vokos, Learner understanding of mechanisms of energy transfer in complex physical processes (unpublished).

[16] S. B. McKagan et al., Energy forms as dynamic tools for understanding complex real-world scenarios (unpublished).

[17] E. Brewe, Energy as a substancelike quantity that flows: Theoretical considerations and pedagogical consequences, Phys. Rev. ST Phys. Educ. Res. 7, 020106 (2011).

[18] R. Duit, Should energy be illustrated as something quasimaterial?, Int. J. Sci. Educ. 9, 139 (1987).

[19] G. Swackhamer, Cognitive resources for understanding energy (unpublished), http://modeling.asu.edu/modeling/ CognitiveResources-Energy.pdf.

[20] R. Millar, Teaching about energy, Department of Educational Studies Research Paper, York University, 2005, http://www.york.ac.uk/media/educationalstudies/ documents/research/Paper11Teachingaboutenergy.pdf.

[21] A. diSessa, Ontologies in pieces: Response to Chi and Slotta, Cognit. Instr. 10, 272 (1993), http://www.jstor.org/ stable/3233731.

[22] G. Falk, F. Herrmann, and G. Bruno Schmid, Energy forms or energy carriers?, Am. J. Phys. 51, 1074 (1983).

[23] T.G. Amin, Conceptual metaphor meets conceptual change, Hum. Dev. 52, 165 (2009).

[24] The description of energy as being located in objects can be a concern for gravitational and other forms of potential energy, which are properly located in a system of objects or in a field, rather than in individual objects. In our instructional contexts, we allow learners to locate such forms of energy either in isolated objects, in systems of objects, or in fields, as is appropriate to the level and learning goals of the course. This approach allows for iterative negotiation and refinement of the meaning of systems, an important learning goal in the study of energy. Alternatively, learners may identify a field as a new kind of (nonmaterial) object that can contain energy.

[25] J. Streeck, C. Goodwin, and C. LeBaron, Embodied interaction in the material world: An introduction, in Embodied Interaction, edited by J. Streeck, C. Goodwin, and C. LeBaron (Cambridge University Press, New York, 2011), pp. 1-28.

[26] C. Goodwin, Action and embodiment within situated human interaction, J. Pragmatics 32, 1489 (2000).

[27] R. Stevens, The missing bodies of mathematical thinking and learning have been found, J. Learn. Sci. 21, 337 (2012).

[28] E. Hutchins and S. Nomura, Collaborative construction of multimodal utterances, in Embodied Interaction, edited by J. Streeck, C. Goodwin, and C. LeBaron (Cambridge University Press, New York, 2011).

[29] T. Koschmann and C. LeBaron, Learner articulation as interactional achievement: Studying the conversation of gesture, Cognit. Instr. 20, 249 (2002).

[30] E. Hutchins and L. Palen, Constructing meaning from space, gesture, and speech, in Discourse, Tools, and Reasoning: Situated Cognition and Technologically Supported Environments, edited by L. B. Resnick et al. (Springer Verlag, Heidelberg, 1997).

[31] G. Lakoff and M. Johnson, Philosophy in the Flesh: The Embodied Mind and Its Challenge to Western Thought (Basic Books, New York, 1999).

[32] G. Lakoff and R.E. Nuñez, Where Mathematics Comes from: How the Embodied Mind Brings Mathematics into Being (Basic Books, New York, 2000).

[33] R. Nuñez, L.D. Edwards, and J.F. Matos, Embodied cognition as grounding for situatedness and context in mathematics education, Educ. Stud. Math. 39, 45 (1999).

[34] M. Singer, J. Radinsky, and S. R. Goldman, The role of gesture in meaning construction, Discourse Process. 45, 365 (2008).

[35] S. C. Broaders, S. W. Cook, Z. Mitchell, and S. GoldinMeadow, Making children gesture brings out implicit knowledge and leads to learning, J. Exp. Psychol. Gen. 136, 539 (2007).

[36] S. W. Cook and S. Goldin-Meadow, The role of gesture in learning: Do children use their hands to change their minds?, J. Cognit. Dev. 7, 211 (2006).

[37] S. W. Cook, Z. Mitchell, and S. Goldin-Meadow, Gesturing makes learning last, Cognition 106, 1047 (2008).

[38] L.D. Edwards, Gestures and conceptual integration in mathematical talk, Educ. Stud. Math. 70, 127 (2009).

[39] K. A. Kastens, S. Agrawal, and L. S. Liben, Research methodologies in science education: The role of gestures in geoscience teaching and learning, J. Geosci. Educ. 56, 362 (2008).

[40] M. Kim, W.-M. Roth, and J. Thom, Children's gestures and the embodied knowledge of geometry, Int. J. Sci. Math. Educ. 9, 207 (2011). 
[41] L. Radford, Why do gestures matter? Sensuous cognition and the palpability of mathematical meanings, Educ. Stud. Math. 70, 111 (2009).

[42] W.-M. Roth and D. V. Lawless, When up is down and down is up: Body orientation, proximity, and gestures as resources, Lang. Soc. 31, 1 (2002).

[43] W.-M. Roth and M. Welzel, From activity to gestures and scientific language, J. Res. Sci. Teach. 38, 103 (2001).

[44] R. Nemirovsky and F. Ferrera, Mathematical imagination and embodied cognition, Educ. Stud. Math. 70, 159 (2009).

[45] E. M. Crowder, Gestures at work in sense-making science talk, J. Learn. Sci. 5, 173 (1996).

[46] R. Nemirovsky, C. Rasmussen, G. Sweeney, and M. Wawro, When the classroom floor becomes the complex plane: Addition and multiplication as ways of bodily navigation, J. Learn. Sci. 21, 287 (2012).

[47] W.-M. Roth and D. V. Lawless, Scientific investigations, metaphorical gestures, and the emergence of abstract scientific concepts, Learn. Instr. 12, 285 (2002).

[48] R.E. Scherr, Gesture analysis for physics education researchers, Phys. Rev. ST Phys. Educ. Res. 4, 010101 (2008).

[49] A. Touval and G. Westreich, Teaching sums of angle measures: A kinesthetic approach, Math. Teach. 96, 230 (2003).

[50] P. M. Ross, D. A. Tronson, and R. J. Ritchie, Increasing conceptual understanding of glycolysis and the Krebs cycle using role play, Am. Biol. Teach. 70, 163 (2008).

[51] V. Singh, The Electron Runaround: Understanding electric circuit basics through a classroom activity, Phys. Teach. 48, 309 (2010).

[52] C. A. Manogue, P. J. Siemens, J. Tate, K. Browne, M.L. Niess, and A. J. Wolfer, Paradigms in Physics: A new upper-division curriculum, Am. J. Phys. 69, 978 (2001).

[53] C. A. Morrow, Kinesthetic Astronomy: The sky time lesson, Phys. Teach. 38, 252 (2000).

[54] E. L. Reinfeld and M. A. Hartman, Kinesthetic life cycle of stars, Astron. Educ. Rev. 7, 158 (2008).

[55] T. Richards, Using kinesthetic activities to teach Ptolemaic and Copernican retrograde motion, Sci. Educ. 21, 899 (2012).

[56] A. Begel, D. D. Garcia, and S. Wolfman, Kinesthetic learning in the classroom, SIGCSE Bull. 36, 183 (2004).

[57] V. Colella, Participatory simulations: Building collaborative understanding through immersive dynamic modeling, J. Learn. Sci. 9, 471 (2000).

[58] M. Resnick and U. Wilensky, Diving into complexity: Developing probabilistic decentralized thinking through role-playing activities, J. Learn. Sci. 7, 153 (1998).

[59] J. P. Chinnicci, J. W. Yue, and K. M. Torres, Students as "human chromosomes" in role-playing mitosis and meiosis, Am. Biol. Teach. 66, 35 (2004).

[60] M. A. Wyn and S. J. Stegink, Role-playing mitosis, Am. Biol. Teach. 62, 378 (2000).

[61] V. Zimmerman, Moving poems: Kinesthetic learning in the literature classroom, Pedagogy 2, 409 (2002).
[62] H. G. Close and P. R. L. Heron, Student understanding of the angular momentum of classical particles, Am. J. Phys. 79, 1068 (2011).

[63] H. Pfister and P. Laws, Kinesthesia-1: Apparatus to experience 1-D motion, Phys. Teach. 33, 214 (1995).

[64] P. Pantidos and S. Patapis, Kinesthetic transverse wave demonstration, Phys. Teach. 43, 344 (2005).

[65] J. Lave, Situating learning in communities of practice, in Perspectives on Socially Shared Cognition, edited by L. B. Resnick, J.M. Levine, and S.D. Teasley (American Psychological Association, Washington, DC, 1991), pp. 63-82.

[66] A. Sfard, On two metaphors for learning and the dangers of choosing just one, Educ. Res. 27, 4 (1998).

[67] A. Sfard, When the rules of discourse change, but nobody tells you: Making sense of mathematics learning from a commognitive standpoint, J. Learn. Sci. 16, 565 (2007).

[68] L. S. Vygotsky, The development of scientific concepts in childhood: The design of a working hypothesis, in Thought and Language, edited by A. Kozulin (Massachusetts Institiute of Technology, Boston, 1986).

[69] J. V. Wertsch, Mediation, in The Cambridge Companion to Vygotsky, edited by H. Daniels, M. Cole, and J. V. Wertsch (Cambridge University Press, New York, 2007).

[70] A. Kendon, Conducting interaction: Patterns of behavior in focused encounters, Studies in Interactional Sociolinguistics (Cambridge University Press, New York, 1990), Vol. 7.

[71] B. Jordan and A. Henderson, Interaction analysis: Foundations and practice, J. Learn. Sci. 4, 39 (1995).

[72] R.D. Pea, Seeing what we build together: Distributed multimedia learning environments for transformative communications, J. Learn. Sci. 3, 285 (1994).

[73] T. Rodden et al., Designing novel interactional workspaces to support face to face consultations, in Proceedings of the Conference on Human Factors in Computing SystemsCHI '03 (ACM Press, Chicago, 2003).

[74] R. Stevens, Divisions of labor in school and in the workplace: Comparing computer and paper-supported activities across settings, J. Learn. Sci. 9, 373 (2000).

[75] E. Hutchins, How a cockpit remembers its speeds, Cogn. Sci. 19, 265 (1995).

[76] F. Erickson, Talk and Social Theory: Ecologies of Speaking and Listening in Everyday Life (Polity Press, Malden, MA, 2004).

[77] R. P. Mcdermott, K. Gospodinoff, and J. Aron, Criteria for an ethnographically adequate description of concerted activities and their contexts, Semiotica 24, 245 (1978).

[78] E. Schegloff, Whose text? Whose context?, Discourse Soc. 8, 165 (1997).

[79] F. Erickson, Qualitative methods in research on teaching, in Handbook of Research on Teaching, edited by M. C. Wittrock (Macmillan, New York, 1986), pp. 119-161.

[80] N. K. Denzin and Y.S. Lincoln, Introduction: The discipline and practice of qualitative research, in The Sage Handbook of Qualitative Research, edited by N. K. Denzin and Y. S. Lincoln (Sage Publications, Thousand Oaks, CA, 2005). 
[81] C. Goodwin, Professional vision, Am. Anthropol. 96, 606 (1994).

[82] K. M. Anderson-Levitt, Ethnography, in Handbook of Complementary Methods in Education Research, edited by J.L. Green et al. (Lawrence Erlbaum Associates, Mahwah, NJ, 2006), pp. 279-295.

[83] R. E. Scherr and D. Hammer, Student behavior and epistemological framing: Examples from collaborative activelearning activities in physics, Cognit. Instr. 27, 147 (2009).

[84] P. Hutchison and D. Hammer, Attending to student epistemological framing in a science classroom, Sci. Educ. 94, 506 (2010).

[85] D. Tannen and C. Wallat, Interactive frames and knowledge schemas in interaction: Examples from a medical examination/interview, in Framing in Discourse, edited by D. Tannen (Oxford University Press, New York, 1993), pp. $57-76$.

[86] G. L. MacLachlan and I. Reid, Framing and Interpretation (Melbourne University Press, Carlton, Victoria, Australia, 1994).

[87] D. Hammer et al., Resources, framing, and transfer, in Transfer of Learning: Research and Perspectives, edited by J. Mestre (Information Age Publishing, Greenwich, CT, 2005), pp. 89-120.

[88] E. Goffman, Frame Analysis: An Essay on the Organization of Experience (Northeastern University Press, Boston, 1986).

[89] W.C. Salmon, Causality and Explanation (Oxford University Press, New York, 1998).

[90] J.A. Maxwell, Using qualitative methods for causal explanation, Field Meth. 16, 243 (2004).

[91] J.A. Maxwell, Causal explanation, qualitative research, and scientific inquiry in education, Educ. Res. 33, 3 (2004).

[92] B. W. Frank and R. E. Scherr, Interactional processes for stabilizing conceptual coherences in physics, Phys. Rev. ST Phys. Educ. Res. 8, 020101 (2012).

[93] R.E. Scherr and E.F. Redish, Newton's zeroth law: Learning from listening to our students, Phys. Teach. 43, 41 (2005).

[94] National Research Council, A Framework for K-12 Science Education: Practices, Crosscutting Concepts, and Core Ideas (National Academies Press, Washington, DC, 2012).

[95] M.E. Loverude, Do students conceptualize energy as a material substance?, in Physics Education Research Conference, Boise, Idaho, 2002, edited by S. V. Franklin, K. Cummings, and J. Marx, http://www.compadre.org/ Repository/document/ServeFile.cfm?ID=4325\&DocID= 1140

[96] American Academy for the Advancement of Science, Benchmarks for Science Literacy (Oxford University Press, New York, 1993).

[97] The role of the Poynting vector in energy transfer in a real electric circuit is not among the learning objectives at the precollege level. See Refs. [103,104].

[98] E. W. Close, H. G. Close, S. B. McKagan, and R.E. Scherr, Energy in action: The construction of physics ideas in multiple modes, AIP Conf. Proc. 1289, 105 (2010).
[99] L. C. McDermott and P. S. Shaffer, Research as a guide for curriculum development: An example from introductory electricity, Part I: Investigation of student understanding, Am. J. Phys. 60, 994 (1992).

[100] D. M. Shipstone, A study of children's understanding of electricity in simple DC circuits, Eur. J. Sci. Educ. 6, 185 (1984).

[101] M. T. H. Chi., J. D. Slotta, and N. De Leeuw, From things to processes: A theory of conceptual change for learning science concepts, Learn. Instr. 4, 27 (1994).

[102] R. Osborne, Towards modifying children's ideas about electric current, Res. Sci. Technol. Educ. 1, 73 (1983).

[103] B.S. Davis and L. Kaplan, Poynting vector flow in a circular circuit, Am. J. Phys. 79, 1155 (2011).

[104] I. Galili and E. Goihbarg, Energy transfer in electrical circuits: A qualitative account, Am. J. Phys. 73, 141 (2005).

[105] R. Chabay and B. Sherwood, Restructuring the introductory electricity and magnetism course, Am. J. Phys. 74, 329 (2006).

[106] E. Ochs, P. Gonzales, and S. Jacoby, "When I come down I'm in the domain state": Grammar and graphic representation in the interpretive activity of physicists, in Interaction and Grammar, edited by E. Ochs, E. Schegloff, and S. Thompson (Cambridge University Press, Cambridge, 1996), pp. 328-369.

[107] R. S. Russ, J.E. Coffey, D. Hammer, and P. Hutchison, Making classroom assessment more accountable to scientific reasoning: A case for attending to mechanistic thinking, Sci. Educ. 93, 875 (2009).

[108] R. S. Russ, R. E. Scherr, D. Hammer, and J. Mikeska, Recognizing mechanistic reasoning in scientific inquiry: A framework for discourse analysis developed from philosophy of science, Sci. Educ. 92, 499 (2008).

[109] D. Hammer and E. van Zee, Seeing the Science in Children's Thinking: Case Studies of Student Inquiry in Physical Science (Heinemann, Portsmouth, NH, 2006).

[110] D. M. Levin et al., Becoming a Responsive Science Teacher: Focusing on Student Thinking in Secondary Science (National Science Teachers Association Press, Arlington, VA, 2013).

[111] R. P. Feynman, R. B. Leighton, and M. Sands, The Feynman Lectures on Physics (Addison-Wesley, Reading, MA, 1969).

[112] National Research Council, National Science Education Standards (National Academy Press, Washington, DC, 1996).

[113] W.H. Kaper and M. J. Goedhart, "Forms of energy," an intermediary language on the road to thermodynamics? Part I, Int. J. Sci. Educ. 24, 81 (2002).

[114] Mechanisms for both transfer and transformation are included in the representation we call Energy Tracking Diagrams, a static graphic representation of energy processes derived from Energy Theater [4].

[115] M. Wiser and S. Carey, When heat and temperature were one, in Mental Models, edited by D. Genter and A. Stevens (Erlbaum, Hillsdale, NJ, 1983), pp. 267-297.

[116] Energy Tracking Diagrams may support similar reasoning [4]. Though these static graphical representations lack the embodied action that is afforded by Energy Theater, they refer to Energy Theater's embodied action, and thus may share some of the same affordances. 